Biodiversity and Conservation

\title{
Identifying population thresholds for flowering plant reproductive success: the marsh gentian (Gentiana pneumonanthe) as a flagship species of humid meadows and heathland \\ --Manuscript Draft--
}

Manuscript Number:

Full Title:

Article Type:

Keywords:

Corresponding Author:

Corresponding Author Secondary

Information:

Corresponding Author's Institution:

Corresponding Author's Secondary Institution:

First Author:

First Author Secondary Information:

Order of Authors:

Order of Authors Secondary Information:

Funding Information:

Abstract:
BIOC-D-17-00267R3

Identifying population thresholds for flowering plant reproductive success: the marsh gentian (Gentiana pneumonanthe) as a flagship species of humid meadows and heathland

Original Research

Demographics; dispersal; habitat fragmentation; Ovule fertilization; Plant conservation; Pollination; Pollen limitation

Simon Pierce, PhD

Universita degli Studi di Milano

Milan, ITALY

Universita degli Studi di Milano

Simon Pierce, PhD

Simon Pierce, PhD

Alberto Spada, PhD

Elisabetta Caporali, PhD

Filippa Puglisi, MSc

Andrea Panzeri, MSc

Alessandra Luzzaro, PhD

Simona Cislaghi, MSc

Lia Mantegazza, MSc

Elisa Cardarelli, $\mathrm{PhD}$

Massimo Labra, PhD

Andrea Galimberti, PhD

Roberta Maria Ceriani, PhD
Fondazione Cariplo
Dr. Simon Pierce

(2014-1631)

The threshold below which population declines impact the effectiveness of plant reproduction is essential for the identification of populations that can no longer spontaneously recover following habitat management or restoration, below the minimum viable population (MVP) size. We hypothesized that risk of reproductive limitation can be evaluated from combined analysis of pollen activity, ovule fertilization and germination in the context of population demographics and fragmentation. The marsh gentian (Gentiana pneumonanthe), a rare emblematic species of European heathland and fen, was investigated at the southern limit of its range in eighteen populations encompassing one to several hundred thousand individuals, spanning 
Response to Reviewers:

small fragments to extensive well-preserved areas. An index of habitat fragmentation was determined from GIS; field surveys determined the ratio of juvenile to reproductive age states; fluorescence microscopy of pistils determined, for each population, the proportion of flowers exhibiting active pollen tube growth. Analysis of seed lots determined the ovule fertilization rate and seed germination capacity. Some of the small populations occupying restricted habitat fragments showed high rates of pollination (100\%) and 'normal' age state demographics. However, reproductive characters all exhibited exponential rise to maximum relationships with population size, indicating clear tipping points (for pollination, at a threshold of 7 reproductive adults, and for ovule fertilization rate and germination at 42 reproductive adults). Thus although small populations may set seed, exhibit a 'normal' age state structure, and may appear viable, reproductive effectiveness declines when population size falls below 42 generative individuals and $<7$ is an indicator of strong limitation. Although many remnant populations of $\mathrm{G}$. pneumonanthe are in the order of 50-150 individuals these should be not be considered as MVPs; they are on the brink of calamity.

We have moved the photographic figures to the online supplementary materials, and recreated the main results figure as suggested. We have removed the species authority (L.) as requested, and we have substituted 'reproductive failure' with phrases such as 'reproductive limitation' and 'decline in reproductive success' in accordance with Reviewer 4's comments. These small changes to the text affect mainly the Abstract but also the opening paragraph of the Introduction and the end of the Discussion.

We thank you for continuing to have faith in this manuscript!

Yours sincerely,

Simon Pierce on behalf of all authors 


\title{
ORIGINAL PAPER
}

\section{Identifying population thresholds for flowering plant reproductive success: the marsh gentian (Gentiana pneumonanthe) as a flagship species of humid meadows and heathland}

\author{
Simon Pierce ${ }^{1}$, Alberto Spada ${ }^{1}$, Elisabetta Caporali ${ }^{2,3}$, Filippa Puglisi ${ }^{4}$, Andrea Panzeri ${ }^{1,7}$, Alessandra \\ Luzzaro $^{1}$, Simona Cislaghi ${ }^{5}$, Lia Mantegazza ${ }^{4}$, Elisa Cardarelli ${ }^{6}$, Massimo Labra ${ }^{5}$, Andrea Galimberti ${ }^{5}$ \\ and Roberta M. Ceriani ${ }^{2}$
}

1 Department of Agricultural and Environmental Sciences (DiSAA), University of Milan, Via G. Celoria 2, I20133 Milan, Italy

2 Department of Biosciences, University of Milan, Via G. Celoria 26, I-20133 Milan, Italy

3 Orto Botanico Città Studi (City of Studies Botanic Garden), University of Milan, Via C. Valvassori Peroni 12, I-20133 Milan, Italy

4 Istituto di Istruzione Superiore Luigi Castiglioni, Via Garibaldi 115, I-20812 Limbiate (MB), Italy

5 Department of Biotechnology and Biosciences,Università degli Studi di Milano-Bicocca, Piazza della Scienza 2, I-20126 Milan, Italy

6 Department of Earth and Environmental Sciences, Università di Pavia, Via Ferrata 9, 27100 Pavia, Italy.

7 The Native Flora Centre of the Lombardy Region (Centro Flora Autoctona; CFA), c/o Consorzio Parco Monte Barro, via Bertarelli 11, I-23851 Galbiate (LC), Italy

Corresponding author: Simon Pierce, simon.pierce @ unimi.it 
1 Abstract The threshold below which population declines impact the effectiveness of plant reproduction is essential for the identification of populations that can no longer spontaneously recover following habitat management or restoration, below the minimum viable population (MVP) size. We hypothesized that risk of reproductive limitation can be evaluated from combined analysis of pollen activity, ovule fertilization and germination in the context of population demographics and fragmentation. The marsh gentian (Gentiana pneumonanthe), a rare emblematic species of European heathland and fen, was investigated at the southern limit of its range in eighteen populations encompassing one to several hundred thousand individuals, spanning small fragments to extensive well-preserved areas. An index of habitat fragmentation was determined from GIS; field surveys determined the ratio of juvenile to reproductive age states; fluorescence microscopy of pistils determined, for each population, the proportion of flowers exhibiting active pollen tube growth. Analysis of seed lots determined the ovule fertilization rate and seed germination capacity. Some of the small populations occupying restricted habitat fragments showed high rates of pollination $(100 \%)$ and 'normal' age state demographics. However, reproductive characters all exhibited exponential rise to maximum relationships with population size, indicating clear tipping points (for pollination, at a threshold of 7 reproductive adults, and for ovule fertilization rate and germination at 42 reproductive adults). Thus although small populations may set seed, exhibit a 'normal' age state structure, and may appear viable, reproductive effectiveness declines when population size falls below 42 generative individuals and $<7$ is an indicator of strong limitation. Although many remnant populations of G. pneumonanthe are in the order of 50-150 individuals these should be not be considered as MVPs; they are on the brink of calamity.

Keywords Demographics, Dispersal, Habitat fragmentation, Ovule fertilization, Plant conservation, Pollination, Pollen limitation 


\section{Introduction}

Habitat fragmentation and declining habitat availability and connectivity induce restricted gene flow within metapopulations, leading to 'Allee effects' (Allee 1931; 1938), and are particularly important for the persistence and conservation of rarer species (Matsumura and Wahitani 2000; Goverde et al. 2002; Pierce et al. 2006). Pollen and seeds are the main vectors of spermatophyte gene flow (Ellstrand 1992) and one of the potential impacts of plant population fragmentation is pollen limitation and subsequent decline in seed production and germination capacity (den Nijs and Oostermeijer 1997; Aguilar et al. 2006): a key aspect of pollen limitation being not only pollen quantity but quality and ability of pollen grains to germinate (Aizen and Harder 2007). Thus aside from the genetic effects of inbreeding depression, one of the main potential impacts of habitat decline is a decline in reproductive success. While identification of reproductive limitations may be relatively straightforward on a case-by-case basis, identifying the general point at which population restriction starts to impact reproductive success for a given species is a delicate problem that requires integration of various aspects of plant biology and ecology. Identification of these thresholds should provide additional information to aid the evaluation of minimum viable population (MVP) sizes for restocking, reintroduction and other conservation activities, as part of wider Population Viability Analysis (PVA; e.g. Menges 2000; Oostermeijer 2000, 2003).

The marsh gentian (Gentiana pneumonanthe: Gentianaceae) provides an example of a 'flagship species' (Volis et al. 2005) for the conservation of European humid meadows and lowland heaths. The importance of microsite availability for seedling establishment and population regeneration for the local persistence of $G$. pneumonanthe is well known (Oostermeijer et al. 1994a), as is the threat of habitat abandonment, succession, competition with tall species and the importance of active habitat management to create gaps for seedling recruitment (Oostermeijer et al. 1996; Kostrakiewicz-Gierałt 2013, 2014). Indeed, the species effectively occupies part of a succession in which reproduction and seedling recruitment become increasingly restricted as succession progresses (Oostermeijer et al. 1996). Seedlings exhibit high mortality rates, but established adults show low mortality and no programmed senescence, although each individual has an idiosyncratic reproductive capacity (Rose et al. 1989). Management techniques such as burning, mowing or sod cutting are all disturbances that have varying impacts on seedling recruitment, the most effective being sod cutting 
(Křenová and Lepš 1996; Oostermeijer et al. 1998). The genetic effects of inbreeding in small populations are also well known for this species: indeed, small populations tend to be less genetically variable and more isolated in terms of gene flow between populations (Raijmann et al. 1994).

However, it is less clear if demographically 'regressive' or 'senile' populations (characterized by limited recruitment; Oostermeijer et al. 1994a; Hegland et al. 2001; Brys et al. 2003) are associated with pollination limitation, and whether this constitutes a problem for the completion of the life cycle and persistence of small groups of plants (in addition to the known impact of successional vegetation development on recruitment opportunities). Knowledge of reproductive limitations is a crucial element for understanding whether population recovery can spontaneously follow habitat management or restoration.

Gentiana pneumonanthe is self-compatible, but has been shown experimentally to exhibit limited autogamy (spontaneous pollination of a flower with its own pollen) due to protandrous flower development (a separate male phase preceding a female phase) and herkogamy (physical separation of anthers and stigmas; Petanidou et al. 1991): autogamy may vary between 0.2 to $25 \%$ depending on circumstances (Petanidou et al. 2001). Gentiana pneumonanthe exhibits nastic corolla movement in response to low temperatures (i.e. flowers close for the night or during cloudy weather at temperatures below $16^{\circ} \mathrm{C}$; Kozuharova 2004) which could press the stigmas lobes close to the anthers, and has been suggested as a mechanism for self-pollination, but could be an adaptation to protect the fertile parts of the flower from chilling and prevent nectar dilution by dew (Kozuharova and Anchev, 2006), or both. Anemophily has also been investigated and is extremely unlikely (Petanidou et al. 1995). It is clear that very small populations can exhibit pollen limitation, with concomitant effects on seed quality and production (Petanidou et al. 1991). However, it would be useful to know at what point these effects start during the decline of populations, as an additional parameter when attempting to determine MVP sizes. Comparison of ovule to seed numbers per fruit across populations suggests that pollination declines towards smaller population sizes, particularly where populations occupy Molinia caerulea-dominated fen habitat where less heath (Calluna vulgaris) is available to support pollinator populations and thus facilitate G. pneumonanthe (Oostermeijer et al. 1998; see also Oostermeijer et al. 2000). The effects of habitat fragmentation and demographic senility are recognized as crucial to the persistence of G. pneumonanthe populations (Oostermeijer et al. 1994a; Volis et al. 2005), but possible relationships between lack of pollination success and population senility (regressive age-state 
structure) have yet to be explicitly tested. Additionally, a view of reproduction at sites at the southern boundary of the species range is currently lacking. Effects of reproductive failure on demographics could be determined by examining a large number of populations across numerous sites and circumstances. Specifically, we ask: at what point do demographic senility, habitat fragmentation and population size become associated with limitation of pollination, ovule fertilization and seed germination capacity?

Measurement of the potential for pollination within plant populations is typically performed by observation of flower visitation by insects to determine the plant-pollinator network, and is ideally complemented by measurement of pollen receipt, or the deposition of pollen on the stigmatic surfaces of the flower (Primack and Silander 1975; Engel and Irwin 2003). This is particularly informative if pollen viability and activity (germination and pollen tube growth; Derksen et al. 1995) can also be confirmed in situ. The growth of the pollen tube and in particular the presence of specific structural compounds in the tube wall allows observation of pollen activity and thus can be used to confirm the viability and efficacy of pollen for flowers collected in the wild. Specifically, the cell wall of the pollen tube is impregnated with the polysaccharide callose, which limits lateral expansion as the pressurized tube grows and avoids inflation of the cell like a balloon (Chebli and Geitmann 2007). As the pollen tube extends, callose-impregnated septa ('plugs') and the action of the cytoskeleton are used to keep gametes at the tip of the tube. Due to this specific structural role of callose it is not found in the tissues of the stigma and underlying style and with the aid of the appropriate stain can thus be used to distinguish pollen tubes from surrounding host tissues. Here we were not interested in the mechanism of pollen tube growth per se (physiological and morphological aspects of which are reviewed by Holdaway-Clarke and Hepler 2003; Chebli and Geitmann 2007), but in assessing the extent to which pollination, ovule fertilization and seed production occur within and between populations, in particular in relation to population demographics and the extent of local habitat fragmentation.

When considered together, observations of the presence of pollen grains, pollen tube growth, penetration of the ovule, ovule development, seed production and germination capacity can provide a high degree of confidence in the effectiveness of reproduction. During fertilization, pollen tube arrival at the ovule initiates ovule and ovary/fruit development, but each ovule requires a viable pollen grain for fertilization and if insufficient grains are deposited this will be evident as a large proportion of ovules that start development but do not contain a zygote, or embryo. Thus measuring the proportion of seeds that contain embryos, or 
not, is a direct indicator of fertilization rate, which may be particularly low in small populations of rare species (e.g. Pierce et al. 2010).

We hypothesized that populations of $G$. pneumonanthe exhibiting senile demographics (i.e. with a small proportion of juveniles; Oostermeijer et al. 1994a) occupying highly fragmented habitats exhibit pollen limitation and subsequent limitation of ovule fertilization and seed germinability, and that thresholds of population size and demographics can be identified to help guide conservation efforts.

\section{Materials and methods}

\section{Study species}

Gentiana pneumonanthe is a perennial scapose hemicryptophyte (i.e. with buds at/just below soil level), with the perennating organ being a rhizome: during winter the aerial parts senesce and several fresh stems may be produced each spring, meaning that despite its herbaceous habit it is essentially deciduous (Simmonds 1946). This allows a polycarpic life history in which flowering can be repeated for decades. The erect stem is thin, but gains some support from surrounding plants, most notably Molinia caerulea, and linear-lanceolate cauline leaves are longer and thinner than the rounder basal leaves and exhibit sufficient stiffness that they may help G. pneumonanthe to maintain its position amongst the upright leaves and stems of $M$. caerulea (when cultivated in isolation, stems of $G$. pneumonanthe are too weak for the plant to stand completely upright, resulting in a trailing habit; S.Pierce, personal observations). This allows large individuals of $G$. pneumonanthe to position an inflorescence at up to $\sim 1.5 \mathrm{~m}$ (typically 10 to $50 \mathrm{~cm}$ ) despite the relatively ephemeral nature of the stems. Flowering takes place from late spring (June), through the summer until October. Fruits contain between 300 and 1000 seeds (Raijmann et al. 1994) which are tiny gravity-dispersed dust seeds that do not appear to persist in soil, and thus the seed bank is transient (Oostermeijer et al. 1992). G. pneumonanthe is the exclusive larval host plant of the critically endangered butterfly Maculinea alcon (Vanden Broeck et al. 2017), and as such plays a key role in the ecology of a range of plant and insect species, including ants (Myrmica spp.; which are also essentially parasitized by M. alcon) and the clumps of Molinia caerulea in which the ants nest. 
Gentiana pneumonanthe is distributed widely in western Europe, from southern Scandinavia and Portugal to Russia, and is found at the southern limit of its range in northern Italy, but the species is restricted to humid meadows (EU Habitats Directive code: 6410 'Molinia meadows on calcareous, peaty or clayey-silt-laden soils (Molinion caeruleae)') and heathland (broadly classifiable as habitat 4030 'European dry heaths', although G. pneumonanthe occupies humid areas; see Cerabolini et al. 2017). The dependence of these habitats on traditional management regimes involving sod cutting and fire means that they are at risk of land-use change and concomitant ecological succession processes.

\section{Study area}

Study sites are listed in Supplementary Table S1 and encompassed lowland heathland dominated by Calluna vulgaris (L.) Hull and Molinia caerulea (L.) Moench (EU Habitats Directive code 4030: European dry heaths) and Molinia meadows on clayey soils (EU 6410: Molinion caeruleae). Sites of particular conservation interest included natural parks in the hinterland of the major conurbation of Milan, including the Groane Regional Park (Parco Regionale delle Groane) and the Briantea Heathland Park (Parco Brughiera Briantea), which include remnants of an historically extensive lowland heathland. A preliminary study, including database records for the occurrence of organisms in the Lombardy region (www.biodiversita.lombardia.it/ossnat_2016/PUBBLICO_flora_elenco_taxa_grid) and onsite inspections, determined that G. pneumonanthe is now locally extinct in many historic sites, including many where the species was observed during a survey of heathland vegetation as late as 2008 (Brusa 2008; Fig. 1).

Habitat area and perimeter were determined from global positioning system track data collected in the field during the summer of 2015 using a Garmin eTrex Summit GPS handset, with track data imported into Quantum GIS (QGIS 2.16 Nødebo; www.qgis.org/en/site) for the creation of polygons from which area and perimeter measurements were obtained. The 'shape index' (SI) of McGarigal and Marks (1995) was used to define the relationship between habitat area and perimeter as detailed in equation 1: 8 89

$$
\mathrm{SI}=\frac{\mathrm{P}}{\mathrm{S}} \times 100
$$


where $\mathrm{P}$ denotes habitat perimeter (in $\mathrm{m}$ ), $\mathrm{S}$ denotes the habitat area $\left(\mathrm{m}^{2}\right)$, and higher values represent larger, relatively irregular (un-circular) fragments.

\section{Demography}

195

For the definition of demographic stages, Oostermeijer et al. (1994a, 1996) identified six age state classes for G. pneumonanthe: 1). seeds, 2). seedlings, 3). juveniles, 4). vegetative adults, 5). generative adults (i.e. in an evident reproductive phase), 6). dormants (winter survival as a rhizome; see also Kostrakiewicz-Gierałt 2013). In practice, during surveys in the summer of 2015, the presence of seeds and dormants was not considered in situ and seedlings and juveniles were considered together, following Volis et al. (2005). Juveniles were defined as individuals with elliptical cauline leaves but with persistent cotyledons, vegetative adults were robust, tall individuals with lanceolate rather than elliptical cauline leaves that were not in bud or in flower, and reproductive adults were those with one or more flower or bud (Fig. 1B-F). The ratio between the number of young plants (Y: seedlings + juveniles) and the number of reproductive or generative adults $(\mathrm{G})$ was used to calculate the age state ratio of Oostermeijer et al. (1994a; Ro) as an indicator of demographic state:

According to Oostermeijer et al. (1994a) a range of values between 0 to 0.029 indicates a 'regressive' or 'senile' population in which juveniles are either absent or very weakly represented, 0.03 to 2 indicates a 'normal' population, and 2 and 100 indicates an 'invasive' population with a preponderance of juveniles. The number of vegetative adults was not used by Oostermeijer et al. (1994a), but was used here for the calculation of other parameters, such as the total number of individuals and the local density of $G$. pneumonanthe.

The number of individuals of each age state at each site was determined from three $9 \mathrm{~m}^{2}$ quadrats (i.e. $\mathrm{R}_{\mathrm{O}}$ values represent a mean with $n=3$ ), with each square centimetre of every quadrat checked manually to soil level for seedlings and other age states. Quadrat size was chosen based on the need to represent the population at the scale of both adults and seedlings. Oostermeijer et al. (1994a) used quadrats of between 4 and $16 \mathrm{~m}^{2}$ based on local population 
density, and an initial study found an intermediate quadrat size of $9 \mathrm{~m}^{2}$ to be manageable and capable of representing all age states and was applied universally across sites to allow standardization. Local population size (in terms of both total population size and number of reproductive adults) was directly counted where possible, but for the largest populations the data from quadrats was used to calculate a density value that, in combination with GIS measurements of site area, was used to estimate local population size (e.g. one of the habitats, at Soave (site 14), had an area of 75.1 hectares and was impossible to survey in its entirety, although spot-checks revealed the presence of G. pneumonanthe apparently throughout).

\section{Pollination success within populations}

'Pollination success rate' was defined as the percentage of individuals within the population that exhibited growth and development of pollen tubes within pistil tissues. For each population, flowers were collected in the female phase of development (Petanidou et al. 2001) in the 2015 field season: generally, 10 flowers per population at the correct developmental stage were found, but sample size ranged from 5 to 15 flowers depending on the amount of available material in nature. Each flower represented a separate individual plant. Flowers were excised at the base and placed in a solution of formalin-acetic-80\% alcohol (1:1:8; FAA) at $\sim 4{ }^{\circ} \mathrm{C}$ (in the field, in a cool-bag over icepacks, in the laboratory in a refrigerator). After $24 \mathrm{~h}$ samples were transferred to $70 \%$ ethanol which was replaced with fresh $70 \%$ ethanol after a further $24 \mathrm{~h}$, followed by longer-term storage at $4{ }^{\circ} \mathrm{C}$.

Pollen tubes were stained and observed following Martin (1959): the calyx and corolla of each flower were excised and tissues were cleared in $8 \mathrm{~N}$ sodium hydroxide solution followed by staining with a $0.1 \%$ solution of water-soluble aniline blue dye dissolved in $0.1 \mathrm{~N}, \mathrm{~K}_{3} \mathrm{PO}_{4}$. The pistil of Gentiana spp. is formed by two carpels, and these were separated longitudinally along the line where they joined, and then both carpels were arranged side-by-side on a microscope slide and observed whole under a conventional fluorescence microscope. Samples were illuminated with ultraviolet light (wavelength $356 \mathrm{~nm}$ ) to stimulate fluorescence of aniline associated with pollen tube callose. The presence or absence of pollen on the stigmatic surface was recorded, and the presence and disposition of pollen tubes within style and carpel wall tissues and in the vicinity of ovules was noted for each sample. 
Seed was collected in autumn 2015 from ten fruits (where possible) from each population using $20 \mathrm{ml}$ capacity polypropylene bottles and stored for two months in the drying room of a

261

262 seed bank maintained at $15 \%$ relative humidity and ambient temperature $\left(\sim 22^{\circ} \mathrm{C}\right)$. Seed mass was measured on a microbalance with a precision of $0.01 \mathrm{mg}$ (model New Classic MS; Mettler-Toledo, Novate Milanese, Italy). For each population seed lots were divided into 6 sub-lots of 50 seeds each, which were weighed and the value divided by 50 to calculate the mean seed mass per sub-lot. These values were used to calculate the mean single seed weight per population.

For germination, Gentiana pneumonanthe is known to germinate on water agar (Godefroid et al. 2010) or on damp filter paper in the light (Oostermeijer et al. 1994b). However, the germination experiment did not aim simply to compare germination rates between populations, but also to produce seedlings and plants for future restocking activities as part of a wider conservation project: it was deemed necessary to provide nutrients for further growth and plant production in a controlled, sterile in vitro system. Murashige and Skoog's (1962) basal medium (from here on referred to as MS) has been used for a range of Gentiana species (Morgan, 2004; Vinterhalter et al. 2012; Kaushal et al. 2014) including G. pneumonanthe (Bach and Pawłowksa 2003). For this motive a half-strength MS medium was used with $15 \mathrm{~g}$ $\mathrm{L}^{-1}$ sucrose and $6 \mathrm{~g} \mathrm{~L}^{-1}$ agar and modified by the addition of inositol $\left(50 \mathrm{mg} \mathrm{L}^{-1}\right)$, thymine $(0.5$ $\mathrm{mg} \mathrm{L}^{-1}$ ) and indole-3-butyric acid (IBA; $0.01 \mathrm{mg} \mathrm{L}^{-1}$ ). The $\mathrm{pH}$ of the medium was adjusted to 5.8 using $0.1 \mathrm{~N} \mathrm{NaOH}$ or $\mathrm{HCL}$ immediately prior to autoclaving at $0.1 \mathrm{MPa}$ and $121^{\circ} \mathrm{C}$ for 20 minutes. Medium was then poured into $6 \mathrm{~cm}$-diameter Petri dishes; the use of Petri dishes, rather than flasks, allowed the use of a stereomicroscope to count germination and determine the presence or absence of embryos within seeds (see Pierce et al. 2015).

For seed sowing, $40 \mathrm{mg}$ sub-samples of seed (G. pneumonanthe seeds are extremely small and samples of 'dust seed' were managed as a powder) were transferred to $1.5 \mathrm{ml}$ Eppendorf tubes and surface sterilised using Wilson's (1915) surface sterilization method. Specifically, seeds were immersed in domestic bleach (i.e. a 5\% (v/v) sodium hypochorite solution, equivalent to $3 \%$ active chlorine) containing $0.1 \%$ Tween surfactant as a wetting agent, for 3 minutes, followed by six rinses in sterilized distilled water in a sterile environment. Previous attempts confirmed that relatively dilute bleach solutions were not effective at surface sterilization for this species (see Panzeri 2015). Seeds were sown using a sterilized stainless 
steel spatula on the agar medium contained in the Petri dishes and subsequently sealed using laboratory film (Parafilm). A minimum of twenty replicate Petri dishes per population were prepared.

Following sowing, Petri dishes were placed in a growth chamber (Snijders Economic Deluxe; Thermo-Lab, Codogno (LO), Italy) with a photoperiod of 12 hours, a measured light intensity of $300 \mu \mathrm{mol} \mathrm{Q} \mathrm{m}{ }^{-1} \mathrm{~s}^{-1}$, and a day/night temperature regime of $20 / 10^{\circ} \mathrm{C}$. Petri dishes were removed weekly and checked qualitatively for the presence of germinated seeds, and the position of Petri dishes within the growth chamber was then re-randomised to minimise the possible effects of local temperature and light variation. Final germination percentage was quantified for each treatment when no further germination was observed, at approximately two months after sowing.

Stereomicroscopic examination of Petri dishes involved counting the number of seeds consisting of only external integuments (representing unfertilized ovules) and the number of seeds containing internal integuments surrounding a visible embryo (intact seeds). 'Fertilization rate' was calculated as the percentage of total seeds that were intact and thus represent successfully fertilized ovules. Germination rate was defined as the percentage of intact seeds for which cotyledons and emerging rhizoid-like trichoblasts were visible after two months.

\section{Results}

\section{Observations of pollination}

Pollen grains were evident under UV light as yellow globular structures with fluorescent pollen tubes visible both on the stigmatic surface and penetrating and growing within the style (Fig. S1). Relatively well-developed (recurved) styles were observed with stigmas covered in germinated pollen grains (Fig. S1A). Relatively young styles that were still straight and evidently at the start of development either did not exhibit pollen grains (Fig. S1B) or pollen grains were visible only on the tip, often with pollen tubes visible within the tissues of the style (Fig. S1C-E).

Pollen tubes were observed to descend from the stigmatic surface, through the style tissues in two strands that eventually penetrating the carpel walls and followed the edge of the 
carpels (the edge that later develops to form the long edge of the dehisced fruit; Fig. S2). Ovules were observed to be inserted in 4-5 parallel rows along this line. From these pollen tube bundles individual pollen tubes were observed to abruptly change course in the vicinity of an ovule, with single pollen tubes each entering a single ovule (Fig. S2A). Ovules closest to the distal (apical) end of the ovary where fertilized first, with a gradient of decreasing fertilization evident moving proximally along the ovary (Fig. S2B). Examples were evident of both successful penetration of ovules by pollen tubes (Fig. S2C) and a complete absence of pollen tubes in the carpel walls (Fig. S2D).

\section{Pollination and reproductive success across sites}

Of the site parameters (habitat/demographic measures) population size was found to be the most strongly significantly correlated with pollination success (i.e. the percentage of flowers sampled from the population confirmed to have active pollen growth within pistil tissues which was in turn correlated with fertilization rate and germination capacity; Table 1). Population size was also strongly correlated with fertilization, seed mass and germination capacity (Table 1). Habitat area and shape index (the latter essentially being the opposite of 'fragmentation') also correlated positively with fertilization rate and germination capacity (Table 1), and shape index also correlated positively with seed mass. Thus larger habitat fragments supported larger populations with more effective fertilization, seed filling and germination. Demographic or age state ratio was correlated positively with habitat area, but not with reproductive characteristics such as pollination success, fertilization, seed mass or germination capacity (Table 1).

Pollination success rate was highly variable between populations, ranging from 0 to $100 \%$ (Fig. 2A). Even some of the smallest populations (e.g. Sites 4, 8 and 9) exhibited 100\% pollination success (Fig. 2A), whereas some of the largest populations exhibited only moderate pollination success: e.g. 50\% for a large population occupying a recently burned area at Rovesenda (Site 18; Fig. 2A). In general, pollination success rate was significantly correlated with population size $\left(\mathrm{R}^{2}=0.578, \mathrm{~F}=10.282, p=0.0015\right)$ following an exponential rise to maximum relationship with a tipping point at 7 reproductive individuals, above which pollination rate was consistently high and below which pollination success declined towards the origin (Fig. 2A). 
The mean fertilization rate also exhibited a statistically significant rise to maximum relationship with population size, with a tipping point at 42 reproductive adults below which fertilization declined to the origin $\left(\mathrm{R}^{2}=0.776, \mathrm{~F}=11.286, p=0.0004\right.$; Fig. 2B). Similarly, germination capacity was consistently around $20 \%$ for populations of more than 42 reproductive adults, but below this tipping point declined in the smallest populations following a similar statistically significant relationship $\left(\mathrm{R}^{2}=0.543, \mathrm{~F}=3.913, p=0.0429\right.$; Fig. 2C).

\section{Discussion}

The results demonstrate that highly variable rates of pollination success experienced by small populations of $G$. pneumonanthe occupying restricted habitat fragments are not directly correlated with the degree of 'senility' or age-state characteristics of populations (i.e. senility does not occur because of pollen limitation). This is in agreement with the observation that recruitment may effectively become disconnected from annual reproductive effort because long-lived individuals persist over decades as the vegetation 'successes' around them, restricting the gaps required for seedling establishment (Oostermeijer et al. 1996). In the present study, several sites with small populations represented remnants of historic heathland that are now so transformed that they essentially represent a woodland understorey composed mainly of $M$. caerulea hosting a few reproductive adults of G. pneumonanthe (e.g. site 4; Table S1). Both recruitment (seedlings) and pollination were absent at these sites and this is a clear sign of local extinction debt (i.e. a time-lag between the effective extinction and when the last individual actually dies). However, for some small populations the extinction debt was less obvious: these exhibited 'normal' age state distributions and appeared to be in demographic good health in appropriate habitat (e.g. the 16 plants at 'Pineta'; Site 8) but reproduction was not as effective as larger populations. Indeed, pollination success exhibited a sharp and significant decline below 7 flowering individuals, and a decline in ovule fertilization rate and germination capacity was evident in populations of less than 42 reproductive adults. This suggests that for small populations pollination was sporadic (despite the fact that autogamy is possible for this species it is apparently not a reliable mechanism) and pollen availability was insufficient to support high fertilization rates - a clear threshold for pollen limitation. While this generally confirms a similar suggestion by Oostermeijer et al. (1998) based on ovule/seed set counts across populations, we can add that our direct 
observation of pollination revealed that the relationship is not linear (the closest fit being an exponential rise to maximum relationship; Fig. 2) and thus a tipping point is evident which represents a threshold for severe reproductive limitation.

A population size of approximately 42 flowering individuals is an important general threshold as many populations in managed habitat fragments (at least in northern Italy) are of this order of magnitude in size, suggesting that any further declines in habitat availability, pollen availability or increased fragmentation will almost certainly prove disastrous. In the present study only certain aspects of the biology and ecology of the species were investigated, and this population size threshold should not be interpreted as a minimum viable population size per se: rather it is the limit below which reproductive limitations become severe. Where a more extensive range of factors are accounted for the minimum viable population size is estimated to be much higher: in the order of 300 to 400 (Oostermeijer et al. 2003), although stochastic environmental effects may alter this estimate (Oostermeijer 2000) and a safer minimum viable population size is likely to be in the order of a thousand individuals (JGB Oostermeijer, personal communication). The majority of populations in the study area are thus well below the minimum viable population size, but hope springs from the fact that reproduction for many populations remains above the thresholds for severe limitation.

A further complication of restricted population size and habitat fragmentation is that of inbreeding, evident for populations in the Netherlands from study of polymorphic isozyme loci (Oostermeijer 1994b; Raijmann et al. 1994). For the populations in the present study, investigation of possible genetic effects of habitat fragmentation including inbreeding depression was beyond the scope of the analysis presented here, but genome ezRADseq-based investigation of material collected from all populations during the study is currently underway and results will be presented separately in the context of the ecological factors and vegetation characters predominating at each site. While traditional studies of genetic variability use neutral genetic markers that are not necessarily pertinent to the ecology of the species, study of genome-scale variability between individuals will be able to determine specific differences across hundreds of alleles that reflect ecological adaptation. Indeed, a future aim will be to understand which populations can provide genetically-compatible material to restore or reinforce neighbouring or even distant populations without inducing out-breeding depression, particularly with regard to the possibility that 'heathland' and 'fen' ecotypes of the species might exist. 
Population restoration should ideal be based on encouraging seedling recruitment by 'resetting' the ecological succession using traditional management techniques such as sod cutting (Oostermeijer et al. 1998). This type of disturbance provides microsites for establishment whilst suppressing competition by surrounding vegetation. Other options include the addition of seed to sites following management or the reinforcement of populations using plants produced ex situ from seed, particularly where there is an urgent requirement to 'boost' a population from the threshold for severe reproductive limitation to the minimum viable reproductive size. The seeds that germinated during the present study produced several thousand plants that are currently being cultivated and reintroduced to reinforce parent populations, particularly those at greatest risk of reproductive limitation. This forms part of an integrated project including habitat management by the various regional parks and bodies involved with the project, and pupils of a local agricultural college learnt in vitro techniques, produced plants and helped with the practical work of mowing habitat and restocking wild populations (Figs. S3-S6). An ultimate aim will be to re-establish lost historic populations using appropriate ecotypes, guided by genetic analysis of the relatedness of extant populations. Notably, the natural parks directly involved in the current project have demonstrated a commitment to the management of their heathland sites and the ideal goal is not simply that of habitat maintenance, but of habitat expansion. Populations of rare perennial species can spontaneously expand in response to appropriate management regimes (Endels et al. 2007) when reproduction is not limited, and this is our hope for G. pneumonanthe in northern Italy.

In conclusion, even very small populations of G. pneumonanthe can exhibit pollination, ovule fertilization and seed set, and are not necessarily senile or regressive. However, populations of less than seven flowering (reproductive or generative) individuals exhibit a statistically significant decline in pollination success, probably representing a shift from outcrossing to highly variable and unreliable autogamy. A threshold of 42 reproductive adults is important for other aspects of reproduction (ovule fertilization, seed germination), above which reproduction is not limited by issues of population size and habitat fragmentation. As suggested by Oostermeijer et al. (2003) minimum viable population sizes are likely to be in the order of several hundred flowering individuals or more. To this we can add that local groups of around 50 flowering adults may appear demographically 'normal' and capable of out-crossing and reproduction, but should nonetheless be considered to be on the cusp of out- 
successful conservation, a threshold of $\sim 50$ flowering plants represents an indicator of direst conservation need.

Acknowledgements This study was supported by a grant from the Cariplo Foundation as part of the project "FraGenziane: Fragmented Gentiana pneumonanthe populations, habitats and associated fauna in local ecological network", grant number 2014-1631: project leader, Parco Monte Barro. The regional parks of Parco Regionale delle Groane and Consorzio Parco Brughiera Briantea allowed access to their territories and actively facilitated the project, and we particularly thank Luca Frezzini and the ecological guards of the Groane Park (particularly Paolo Ventura and Antonella Pezzotta) and Daniele Piazza of Consorzio Parco Brughiera Briantea. We thank Dr. Maria Costanza Scarpini (Istituto L. Castiglioni) and students of the school for their enthusiasm whilst actively facilitating investigation of seed germination and plant production. We thank Guido Brusa for sharing his experience and for help with finding populations. Prof. Giuseppe Bogliani coordinated project activities for the University of Pavia, and Silvia Stefanelli and Arianna Musacchio provided entomological assistence in the field. We thank Letizia Manzoni for help with the analysis of autogamy. Prof. Maurizio Cornalba (University of Pavia) shared his expertise for the determination of Apoidea. We thank the regional governments of Lombardy and Piedmont for permission to collect samples of plant material. Comments from three anonymous reviewers, one of whom left strong hints as to their identity, greatly improved the manuscript and in doing so improved the chances of survival of G. pneumonanthe in northern Italy.

Author contribution statement SP and RMC conceived and designed the study, SP, EC (Caporali), AS and AL performed the pollination analyses, SP, FP, LM, AL, AP and SC collected flowers and seed, characterized seed lots and performed in vitro germination tests for the study populations. ML and AG supervised population sampling, advised on statistics and revised the text. EC (Cardarelli) performed the analysis of pollinator visitation. SP performed statistical tests, produced graphics and wrote the manuscript, and all authors were involved in manuscript correction.

\section{Supplementary material}

Data analysed during this study are available as supplementary online material in the form of a spreadsheet file. 


\section{References}

Aizen MA, Harder LD (2007) Expanding the limits of the pollen-limitation concept: effects of pollen quantity and quality. Ecology 88(2):271-281

Aguilar R, Ashworth L, Galetto L, Aizen MA (2006) Plant reproductive susceptibility to habitat fragmentation: review and synthesis through a meta-analysis. Ecology Letters 9(8):968-980

Allee WC (1931) Animal aggregations, a study in general sociology. University of Chicago Press, Chicago.

Allee WC (1938) The social life of animals. Norton, New York

Bach A, Pawłowksa B (2003) Somatic embryogenesis in Gentiana pneumonanthe L.. Acta Biologica Cracoviensia Series Botanica 45(2):79-86

Brusa G (2008) Study of heath (Calluna vulgaris) vegetation formations of the Brughiera Briantea Park and the Province of Como (original title, Studio delle formazioni vegetali a brugo (Calluna vulgaris) del Parco Brughiera Briantea e della Provincia di Como). Consorzio del Parco Brughiera Briantea (in the Italian language)

Brys R, Jacquemyn H, Endels P, Hermy M, De Blust G (2003) The relationship between reproductive success and demographic structure in remnant populations of Primula veris. Acta Oecologica 24:247-253

Cerabolini BEL, Brusa G, Ceriani RM, Armiraglio S, De Molli C, Pierce S (2017) Ecology and floristic composition of heathlands in the Po basin and the Southern Alps (NW Italy). Botany Letters (in press: doi: 10.1080/23818107.2017.1387077)

Chebli Y, Geitmann A (2007) Mechanical principles governing pollen tube growth. Functional Plant Science and Biotechnology 1(2):232-245

den Nijs HCM, Oostermeijer JGB (1997) Reproductive biology and gene flow in a fragmented landscape. Bocconea 7:153-165

Derksen J, Rutten T, Van Amstel T, De Win A, Doris F, Steer M (1995) Regulation of pollen tube growth. Acta Botanica Neerlandica 44(2):93-119

Ellstrand NC (1992) Gene flow by pollen, implications for plant conservation genetics. Oikos 63:77-86

Endels P, Jacquemyn H, Rein B, Hermy, M (2007) Reinstatement of traditional mowing regimes counteracts population senescence in the rare perennial Primula vulgaris. Applied Vegetation Science 10:351-360

Engel EC, Irwin RE (2003) Linking pollinator visitation rate and pollen receipt. American Journal of Botany 90(11):1612-1618

Goverde M, Schweizer K, Baur B, Erhardt A (2002) Small-scale habitat fragmentation effects on pollinator behaviour, experimental evidence from the bumblebee Bombus veteranus on calcareous grasslands. Biological Conservation 104:293-299

Hegland SJ, van Leeuwen M, Oostermeijer JGB (2001) Population structure of Salvia pratensis in relation to vegetation and management of Dutch dry floodplain grasslands. Journal of Applied Ecology 38:1277-1289

Hofhanzlová E, Křenová Z (2007) Pollination strategy and reproductive success of Gentiana pannonica in a natural population. Silva Gabreta 13(2):83-94

Holdaway-Clarke TL, Hepler PK (2003) Control of pollen tube growth, role of ion gradients and fluxes. Tansley Review. New Phytologist 159:539-563 
Kaushal S, Sidana A, Dev K (2014) In vitro plant production through apical meristem culture of Gentiana kurroo Royle. Journal of Medicinal Plants Studies 3(1):4-9

Kostrakiewicz-Gierałt K (2013) The effect of vegetation character on abundance and structure of subpopulations of rare herb species Gentiana pneumonanthe L. Polish Journal of Ecology 61(1):35-46

Kostrakiewicz-Gierał K (2014) The effect of neighbouring plant height, disturbance level and gap size on spontaneous recruitment of large-seeded and small-seeded species in Molinietum caeruleae Meadows. Polish Journal of Ecology 62(2):289- 306.

Kozuharova E (2004) Pollination ecology of Gentiana asclepiadea L. and G. pneumonanthe L. (Gentianaceae, Sect. Pneumonanthe) in Bulgaria. Annual of Sofia University "St. Kliment Ohridski”, Faculty of Biology, Book 2 - Botany 94-96:39-58

Křenová Z, Lepš J (1996) Regeneration of a Gentiana pneumonamthe population in an oligotrophic wet meadow. Journal of Vegetation Science 7: 107-112.

Martin FW (1959) Staining and observing pollen tubes in the style by means of fluorescence. Stain Technology 34(3):125-128

Matsumura C, Wahitani I (2000) Effects of population size and pollinator limitation on seed-set of Primula sieboldii populations in a fragmented landscape. Ecol. Res. 15:307-322

McGarigal K, Marks BJ (1995) Fragstats, spatial pattern analysis program for quantifying landscape structure. General Technical Report PNW-GTR-351, USDA Forest Service, Pacific Northwest Research Station, Portland. pp. 134

Menges ES (2000) Population viability analyses in plants: challenges and opportunities. TREE 15(2):51-56

Morgan ER (2004) Use of in ovulo embryo culture to produce interspecific hybrids between Gentiana triflora and Gentiana lutea. New Zealand Journal of Crop and Horticultural Science 32:343-347

Murashige T, Skoog F (1962) A revised medium for rapid growth and bio assays with tobacco tissue cultures. Physiologia Plantarum 15:473-497

Oostermeijer JGB (2000) Population viability analysis of the rare Gentiana pneumonanthe: the importance of genetics, demography and reproductive biology. In: A.G. Young \& G. M. Clarke (eds.) Genetics, Demography and Viability of Fragmented Populations. Cambridge University Press, Cambridge, UK. pp. 313-334

Oostermeijer JGB, Nijs JCM, Raijmann LEL, Menken SBJ (1992) Population biology and management of the marsh gentian (Gentiana pneumonanthe L.), a rare species in The Netherlands. Botanical Journal of the Linnean Society 108 (2):117-130

Oostermeijer JGB, Van’t Veer R, den Nijs JCM (1994a) Population structure of the rare, long-lived perennial Gentiana pneumonanthe in relation to vegetation and management in the Netherlands. The Journal of Applied Ecology 31:428-438

Oostermeijer JGB, van Eijck MW, den Nijs JCM (1994b) Offspring fitness in relation to population size and genetic variation in the rare plant species Gentiana pneumonanthe (Gentianaceae). Oecologia 97:289-296

Oostermeijer JGB, Brugman ML, De Boer ER, Den Nijs HCM (1996) Temporal and spatial variation in the demography of Gentiana pneumonanthe, a rare perennial herb. Journal of Ecology 84:153-166 
Oostermeijer JGB, Luijten SH, Krenova ZV, Den Nijs HCM (1998) Relationships between population and habitat characteristics and reproduction of the rare Gentiana pneumonanthe L. Conservation Biology 12(5):1042-1053

Oostermeijer JGB, Luijten SH, Petanidou T, Kos M, Ellis-Adam AC, Den Nijs JCM (2000) Pollination in rare plants: is population size important? Det Norske Videnskaps Akademi. I. Matematisk Naturvidenskapelige Klasse, Skrifter, Ny Serie 39:201 -213

Oostermeijer JGB, Luijten SH, Den Nijs JCM (2003) Integrating demographic and genetic approaches in plant conservation. Biological Conservation 113:389-398

Panzeri A (2015) Monitoraggio della fioritura, propagazione da seme e coltivazione della rara Gentiana pneumonanthe a fini conservazionistici. Masters Thesis, Department of Agricultural and Environmental Sciences (DiSAA), University of Milan, Italy (in the Italian language)

Petanidou T, Den Nijs HCM, Ellis-Adam AC (1991) Comparative pollination ecology of two rare Dutch Gentiana species, in relation to population size. Acta Horticulturae 288:308-312

Petanidou T, Den Nijs HCM, Oostermeijer JGB, Ellis-Adam AC (1995) Pollination ecology and patchdependent reproductive success of the rare perennial Gentiana pneumonanthe. New Phytologist 129:155163

Petanidou T, Ellis-Adam AC, Den Nijs HCM, Oostermeijer JGB (2001) Differential pollination success in the course of individual flower development and flowering time in Gentiana pneumonanthe L. (Gentianaceae). Botanical Journal of the Linnean Society 135:25-33

Pierce S, Ceriani RM, Villa M, Cerabolini B (2006) Quantifying relative extinction risks and targeting intervention for the orchid flora of a natural park in the European pre-alps. Conservation Biology 20(6):1804-1810

Pierce S, Ferrario A, Cerabolini B (2010) Outbreeding and asymbiotic germination in the conservation of the endangered Italian endemic orchid Ophrys benacensis. Plant Biosystems 144(1):121-127

Pierce S, Guidi V, Ferrario A, Ceriani RM, Labra M, Vagge I, Cerabolini BEL (2015) Pea seed extracts stimulate germination of the terrestrial orchid Ophrys apifera Huds. during a habitat restoration project. Plant Biosystems 149(1):54-60

Raijmann LEL, van Leeuwen NC, Kersten R, Oostermeijer JGB, den Nijs HCM, Menken SBJ (1994) Genetic variation and outcrossing rate in relation to population size in Gentiana pneumonanthe L. Conservation Biology 8:1014-1026

Rose RJ, Clarke RT, Chapman SB (1998) Individual variation and the effects of weather, age and flowering history on survival and flowering of the long-lived perennial Gentiana pneumonanthe. Ecography 21: 317 326

Simmonds NW. (1946) Biological flora of the British Isles, Gentiana pneumonanthe L. Journal of Ecology 33:295-307

Vinterhalter B, Milošević DK, Janković T, Milojević J, Vinterhalter D (2012) In vitro propagation of Gentiana dinarica Beck. Central European Journal of Biology 7(4):690-697

Volis S, Bohrer G, Oostermeijer G, Van Tienderen P (2005) Regional consequences of local population demography and genetics in relation to habitat management in Gentiana pneumonanthe. Conservation Biology 19:357-367 
601 Wilson JK (1915) Calcium hypochlorite as a seed sterilizer. American Journal of Botany 2:420-424 602 
Table 1. Pearson's correlation coefficients $(r)$ between population/habitat characters and reproductive 604 characteristics of Gentiana pneumonanthe populations in northern Italy. Enboldened values represent significant 605 correlations: the critical value of $r$ is 0.456 (at the $p \leq 0.05$ level and with $d . f .=17$ ). $\mathrm{R}_{\mathrm{O}}=$ Oostermeijer et al.'s 606 (1994a) age state ratio of young plants (seedlings + juveniles) to reproductive adult individuals.

607

\begin{tabular}{lrrrrrrrr}
\hline Variables & $\begin{array}{r}\text { Population } \\
\text { size }\end{array}$ & $\begin{array}{r}\text { Demographic } \\
\text { ratio }\left(R_{0}\right)\end{array}$ & $\begin{array}{r}\text { Habitat } \\
\text { area }\end{array}$ & $\begin{array}{r}\text { Shape } \\
\text { index }\end{array}$ & $\begin{array}{r}\text { Pollination } \\
\text { success }\end{array}$ & $\begin{array}{r}\text { Fertilization } \\
\text { rate }\end{array}$ & $\begin{array}{r}\text { Germination } \\
\text { capacity }\end{array}$ & $\begin{array}{r}\text { Seed } \\
\text { mass }\end{array}$ \\
\hline Population size & $\mathbf{1}$ & 0.394 & $\mathbf{0 . 7 5 2}$ & $\mathbf{0 . 6 8 0}$ & $\mathbf{0 . 6 1 6}$ & $\mathbf{0 . 7 1 5}$ & $\mathbf{0 . 5 8 7}$ & $\mathbf{0 . 5 8 3}$ \\
Demographic ratio & 0.394 & $\mathbf{1}$ & $\mathbf{0 . 4 6 0}$ & 0.457 & 0.190 & 0.248 & 0.113 & 0.227 \\
Ro) & & & & & & & & \\
Habitat area & $\mathbf{0 . 7 5 2}$ & $\mathbf{0 . 4 6 0}$ & $\mathbf{1}$ & $\mathbf{0 . 9 7 7}$ & 0.206 & $\mathbf{0 . 5 2 8}$ & $\mathbf{0 . 4 8 8}$ & 0.424 \\
Shape index & $\mathbf{0 . 6 8 0}$ & 0.457 & $\mathbf{0 . 9 7 7}$ & $\mathbf{1}$ & 0.170 & $\mathbf{0 . 5 2 2}$ & $\mathbf{0 . 5 3 1}$ & $\mathbf{0 . 4 3 1}$ \\
Pollination success & $\mathbf{0 . 6 1 6}$ & 0.190 & 0.206 & 0.170 & $\mathbf{1}$ & $\mathbf{0 . 6 0 0}$ & $\mathbf{0 . 5 0 6}$ & 0.350 \\
Fertilization rate & $\mathbf{0 . 7 1 5}$ & 0.248 & $\mathbf{0 . 5 2 8}$ & $\mathbf{0 . 5 2 2}$ & $\mathbf{0 . 6 0 0}$ & $\mathbf{1}$ & $\mathbf{0 . 7 5 6}$ & $\mathbf{0 . 8 7 7}$ \\
Germination capacity & $\mathbf{0 . 5 8 7}$ & 0.113 & $\mathbf{0 . 4 8 8}$ & $\mathbf{0 . 5 3 1}$ & $\mathbf{0 . 5 0 6}$ & $\mathbf{0 . 7 5 6}$ & $\mathbf{1}$ & $\mathbf{0 . 5 3 5}$ \\
Seed mass & $\mathbf{0 . 5 8 3}$ & 0.227 & 0.424 & $\mathbf{0 . 4 3 1}$ & 0.350 & $\mathbf{0 . 8 7 7}$ & $\mathbf{0 . 5 3 5}$ & $\mathbf{1}$ \\
\hline
\end{tabular}




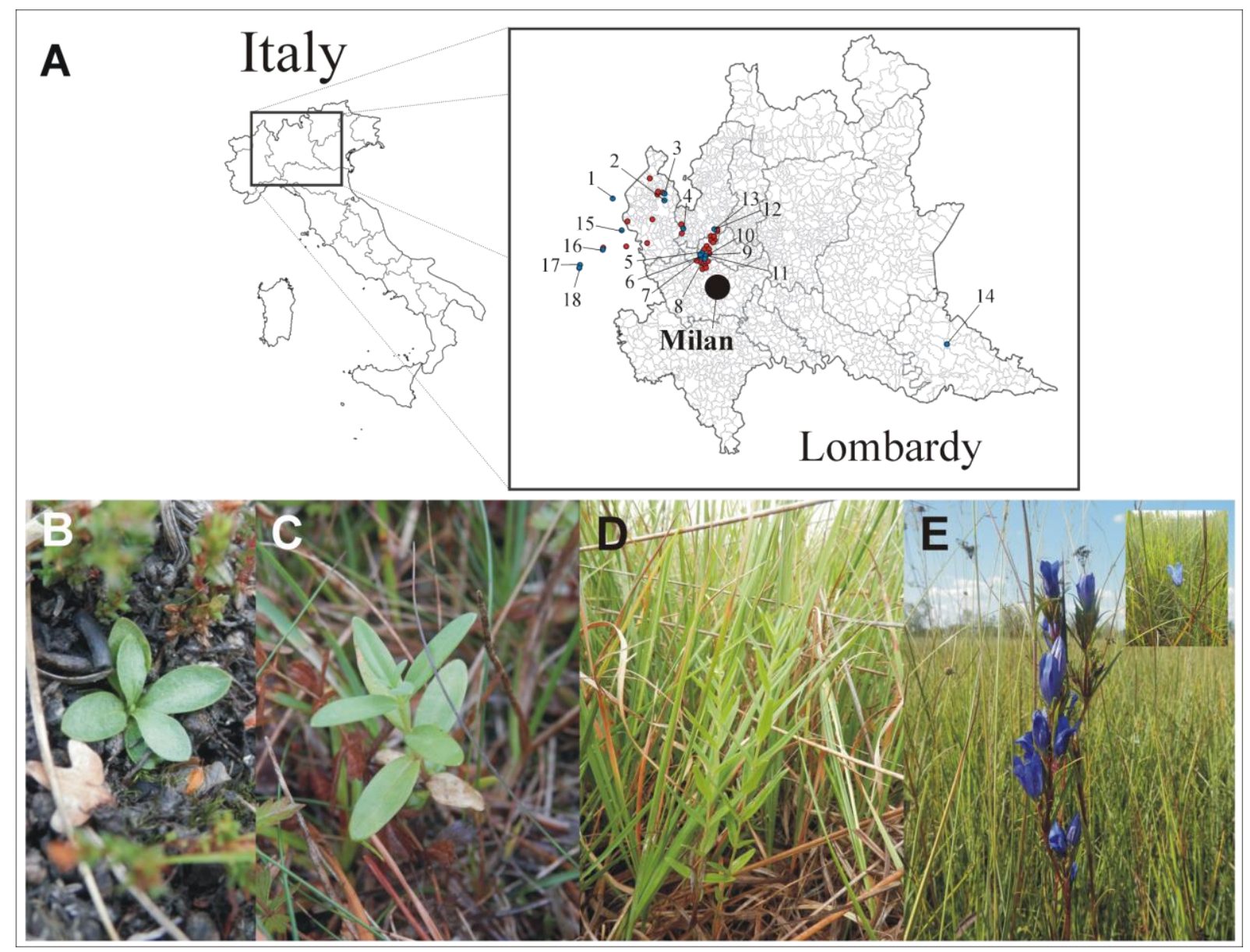

610

612 Fig. 1 Gentiana pneumonanthe populations investigated during the study and an overview of 613 age state categories. A). location of study sites in northern Italy (mainly in the Lombardy 614 region, but some sites in neighbouring Piedmont). Blue points represent sites from which 615 flower and seed material of G. pneumonanthe was collected and vegetation surveys carried 616 out (site labels and names are listed in Supplementary Table S1). Red points represent historic 617 records or recent observations for which site inspections confirmed local extinction (site 618 labels not reported). Age state categories include: B). seedling, C). juvenile, D). vegetative 619 adult, E). reproductive/generative adult with multiple or (inset) single flowers. (Photos: Simon 620 Pierce). 

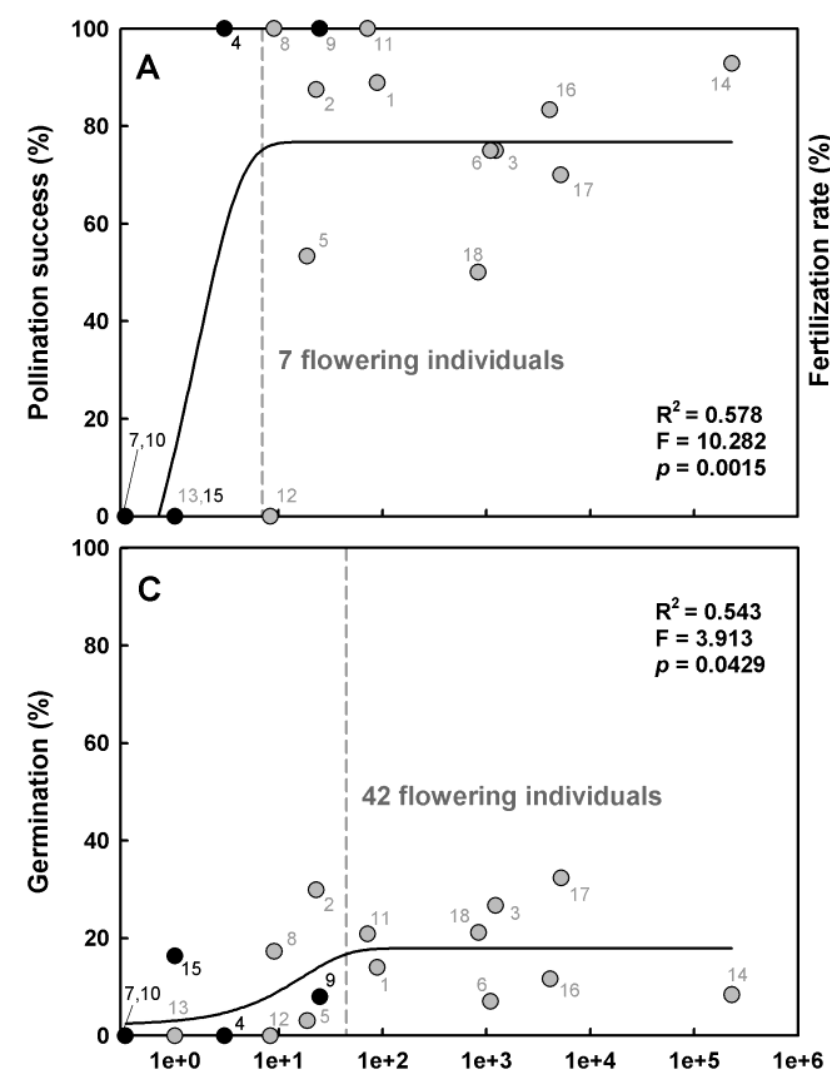

Number of reproductive adults (log number of individuals)

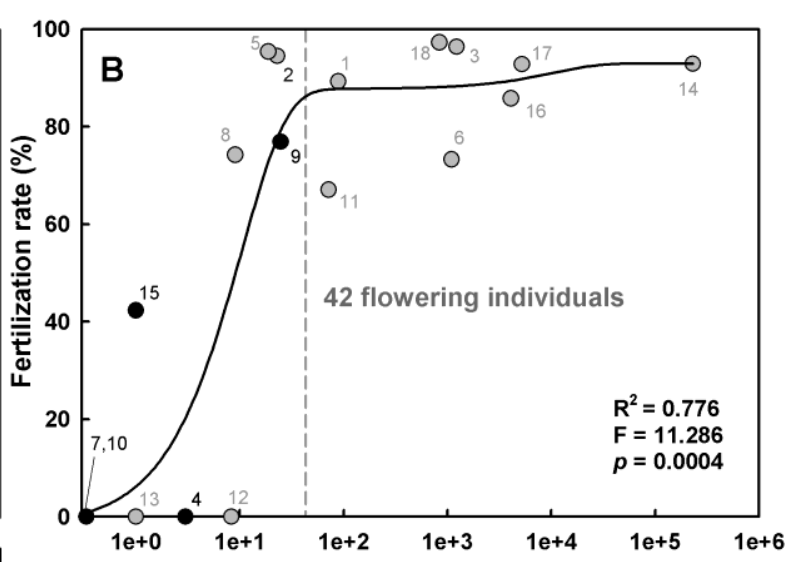

Number of reproductive adults (log number of individuals)

Population age state structure $\left(R_{0}\right) \bullet=$ Regressive $\bigcirc=$ Normal

623 Fig. 2 The relationship between reproductive success (A, pollination success; B, fertilization 624 rate; $\mathrm{C}$, germination capacity in vitro) and population size (log axis) for a wide range of 625 contrasting populations of Gentiana pneumonanthe from northern Italy (code numbers 626 represent populations listed in Table S1). Non-linear regression was fitted as an exponential 627 rise to maximum (double, 5 parameter) followed by ANOVA. Population age state structure 628 represents the ratio of young plants (seedlings + juveniles) to reproductive adult individuals, 629 following the age states delimited by Oostermeijer et al. (1994a). 
Attachment to Manuscript

Click here to view linked References

Click here to access/download Attachment to Manuscript Pierce - Supplementary figures.pdf 
Attachment to Manuscript

Click here to view linked References

\section{Click here to access/download Attachment to Manuscript
Pierce - Supplementary Table S1.pdf Attachment to Manuscript
Pierce - Supplementary Table S1.pdf}


Click here to access/download Attachment to Manuscript Pierce - Pollinator observation sub-study.pdf 
Click here to access/download Attachment to Manuscript Pierce et al Gentiana pneumonanthe data.xlsx 